\title{
Médiévales
}

Langues, Textes, Histoire

$64 \mid$ printemps 2013

Temporalités de l'Égypte

\section{Anne GERSTEN, De la grande déesse à la vierge en majesté, histoire d'un mythe par l'image}

Bruxelles, Académie royale de Belgique, coll. «Classe des Arts », 2011, $168 \mathrm{p}$.

Charles Avril

\section{CpenEdition}

Journals

Édition électronique

URL : https://journals.openedition.org/medievales/7057

DOI : 10.4000/medievales.7057

ISSN : 1777-5892

Éditeur

Presses universitaires de Vincennes

Édition imprimée

Date de publication : 1 juillet 2013

Pagination : 216-218

ISBN : 978-2-84292-371-6

ISSN : 0751-2708

Référence électronique

Charles Avril, «Anne gERSTEN, De la grande déesse à la vierge en majesté, histoire d'un mythe par l'image », Médiévales [En ligne], 64 I printemps 2013, mis en ligne le 09 septembre 2013, consulté le 24 avril 2022. URL : http://journals.openedition.org/medievales/7057 ; DOI : https://doi.org/10.4000/ medievales. 7057

Ce document a été généré automatiquement le 24 avril 2022.

Tous droits réservés 


\section{Anne GERSTEN, De la grande déesse à la vierge en majesté, histoire d'un mythe par l'image}

Bruxelles, Académie royale de Belgique, coll. «Classe des Arts », 2011, $168 \mathrm{p}$.

\section{Charles Avril}

1 Anne Gersten aborde une des plus grandes dévotions médiévales, celle du culte en l'honneur de Marie. Cette étude d'histoire de l'art s'articule autour de deux axes principaux: l'étude iconographique du type Sedes Sapientiae, particulièrement deux exemplaires mosans, c'est-à-dire la Vierge assise sur un trône portant dans ses bras le Christ-Enfant, et la relation entre le culte de la déesse Mère et celui de la Theotokos. L'auteur y consacra un mémoire à l'Université de Liège au début des années 1970

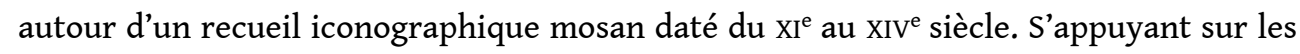
travaux d'Erwin Panofsky, Essais d'iconologie et d'Hans Belting, Image et culte : une histoire de l'image avant l'époque de l'art, l'auteur définit l'image et la qualité d'une œuvre d'art sur « son pouvoir de communication de l'idée qu'elle contient » (p. 11), ce qui aiguillera sa réflexion tout au long de l'ouvrage.

Dans un premier temps l'auteure, inspirée par les travaux archéologiques de James Mellaart et Jacques Cauvin, présente le concept de déesse Mère à partir des petites Vénus paléolithiques. Émergeant à l'époque du néolithique, ce culte traverserait toutes les cultures du Proche Orient à la Grèce préhellénique en passant par l'Europe, et se caractériserait par une vénération d'une Mère universelle assise sur un trône qui incarne la vie/la mort/la renaissance. L'auteur voit dans les premières civilisations agraires indo-européennes «le passage progressif de la Déesse-Mère souveraine au Dieu-Père » (p. 46), tout en distinguant une continuité de la déesse Mère. Si ce culte ne s'exprime plus dans les mêmes termes que lors de la première période, il se mute en quelque sorte à travers de nombreuses déesses des populations étudiées (mésopotamiennes, égyptiennes, grecques, cananéennes, romaines, celtes et galloromaines), ainsi que dans les religions à mystères. A. Gersten perçoit particulièrement 
dans le culte d'Isis un parallèle avec le culte marial. Elle aborde enfin la question iconographique et constate la permanence de la figuration d'un trône pour représenter ces déesses. Développée au $\mathrm{VII}^{\mathrm{e}}$ siècle avant notre ère, la posture hiératique se fait cependant plus rare aux époques classique et hellénistique. Une première limite doit être mentionnée à ce moment de l'étude au sujet de la Bible. L'auteure affirme que «le dieu unique prend toutes les fonctions religieuses» (p.58) et qu'il s'agit alors de la domination du Dieu-Père. Or, dans le livre de la Genèse, un verset vient bousculer cette conception puisqu'au sujet de la création d'Adam il est écrit : " Dieu créa l'homme à son image, à l'image de Dieu il le créa : mâle et femme il les créa ». Les citations où Dieu se confond avec une mère sont nombreuses (par exemple Is 49,15). La paternité divine biblique n'est pas strictement liée au géniteur masculin mais renvoie plus largement à la parenté divine. Enfin l'auteure présente l'avènement du christianisme dans ses grandes lignes historiques et son rapport avec l'image. Si l'auteure précise plusieurs fois que Marie est un objet historique singulier, certains parallèles ne sont pas convaincants. Tout d'abord l'auteur considère l'adoration des mages comme une adoration mariale, ce que ne prouve ni le texte évangélique relatif à l'événement ni l'iconographie proposée, à savoir une représentation dans la catacombe de sainte Priscille à Rome du $\mathrm{III}^{\mathrm{e}}$ siècle. La question de l'Immaculée Conception est traitée rapidement sans renvoyer à des travaux plus récents comme ceux de Marielle Lamy. Enfin, le parallèle entre Isis lactans et Maria lactans est des plus curieux. Ne reposant sur aucun fondement théologique, l'auteure le définit en raison du geste commun de Marie et d'Isis portant la main à leurs poitrines pour nourrir l'enfant qu'elles portent. Or ce geste n'est-il pas commun à toutes les femmes qui allaitent leur enfant?

3 L'auteure propose, en se fondant sur de nombreuses illustrations présentes dans l'ouvrage, une typologie de la Sedes Sapientiae, «image [qui] recouvre ainsi le double sens : lieu de la conception divine en tant que mère de Dieu (Siège de la Sagesse) et siège en tant que support matériel » (p.124), formant ainsi une synthèse claire sur cette représentation mariale. A.Gersten expose deux origines de cette forme de représentation de la Vierge: la représentation de l'empereur dans la tradition byzantine d'une part, et le développement des images-reliquaires qui se répandent en Europe autour $\mathrm{du} \mathrm{IX}^{\mathrm{e}}$ siècle d'autre part. La première a inspiré l'Orient chrétien, formant $a u I^{e}$ siècle «le prototype " de la Vierge en majesté donnant le caractère hiératique de cette statue. La seconde est l'origine de l'aspect étincelant et lumineux la " couvrant d'or et d'argent et pierres précieuses » (p. 120), aboutissant à la majesté d'or de Marie. Passant par les vierges romanes et les vierges noires, l'ouvrage semble faire apparaître une chronologie. L'émergence de l'image au $\mathrm{xl}^{\mathrm{e}}$ siècle dans le Midi de la France entraîne une diffusion européenne à travers trois facteurs que recense l'auteur : le développement des pèlerinages, où les pèlerins et les artistes prennent modèle sur la Vierge vénérée en ces lieux comme celui de Chartres ; le succès se manifeste également, selon Anne Gersten, dans le fait que la Vierge en majesté se fixe sur le tympan des cathédrales et se multiplie comme l'attestent les représentations qu'elle qualifie de " populaires ", en s'appuyant sur la thèse d'André Gabar. Enfin, elle aborde la façon dont s'articule la transition entre les Sedes Sapientiae et les Vierges gothiques qualifiées de «Belles Madones». Si paradoxalement cette évolution signifie "à la fois l'apothéose mais aussi la fin du concept de Sedes Sapientiae» (p. 142), elle marque le passage progressif du symbole de l'Incarnation à celui de la maternité divine de Marie. Deux vierges d'origine mosane sont particulièrement étudiées, à savoir la Sedes Sapientiae d'Évegnée du XI ${ }^{e}$ siècle et une Vierge de la collégiale Saint-Jean l'Évangéliste à Liège, 
datant du XIII ${ }^{e}$ siècle, puisqu'elles sont à l'origine de l'ouvrage. Dans cette classification, Anne Gersten revient notamment sur les couleurs utilisées: le bleu pour la pureté, le rouge pour la royauté, l'or pour la divinité et le noir, dans le cas des vierges noires, pour la fécondité, pour la fertilité de celle qui fut fécondée par l'Esprit Saint. L'auteure $\mathrm{y}$ voit une des manifestations des liens qui font que le culte marial serait le prolongement du culte rendu à la déesse Mère.

4 Les analogies recherchées par A. Gersten dans cet ouvrage sont intéressantes dans la mesure où il relève une commune représentation de la féminité et de la royauté. L'ouvrage Marie. Le culte de la Vierge dans la société médiévale, sous la direction de Dominique Iogna-Prat, Éric Palazzo et Daniel Russo, aurait pu apporter des compléments à cette étude. Par ailleurs, voir une continuité du culte de la Déesse Mère dans le culte marial est une orientation qu'il est difficile de suivre en raison du manque de considération de la spécificité des monothéismes et du christianisme, plus particulièrement de l'histoire de la théologie mariale, bien que l'auteure précise dès l'introduction que son paradigme d'étude "n'est cependant pas unanimement partagée » (p. 9). Si cette étude fournit une synthèse, iconographiquement riche sur les Sedes Sapientiae, les conclusions sont cependant l'objet de débats et de controverses. 